\title{
Caracterización jurídica del crédito al consumo en la Comunidad Europea (Directiva No. 2008/48/CEE/CE) ${ }^{(*)}$
}

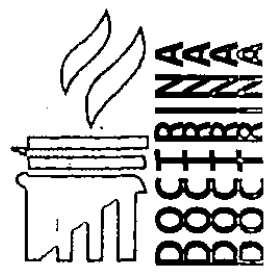

Maria del Carmen Gete-Alonso y Calera

Catedrática de Derecho Civil de la Universidad Autónoma de Barcelona.

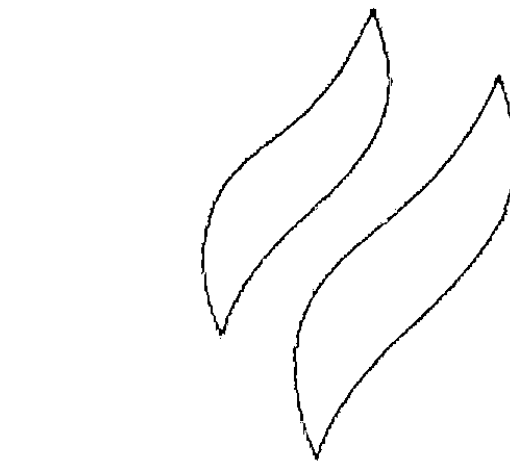

SUMARI0:

I. Introducción:

1. La normativa comunitaria;

2. La legislación española.

II. Contrato de crédito al consumo: Presupuestos:

1. Las definiciones legales;

2. Los datos legales previos.

III. Contrato de préstamo/contrato de crédito:

1. El préstamo mutuo codificado;

2. El contrato de crédito.

IV. El contrato de crédito al consumo:

1. Datos legales de configuración;

2. El régimen jurídico mínimo.

de Derecho de la Universid. Ca lo A. Mispiembro y Ex-Director General de la Revista ADVOCATUS, por la cesión del preseńtelartículo. 


\section{INTRODUCCIÓN}

El crédito al consumo como forma de financiación está estrechamente vinculado a la economía, se origina en ella como consecuencia de una realidad compleja en la que, frente al tradicional crédito a la producción', se presenta como un medio eficaz para el consumidor, de disponer de medios que le permiten realizar intercambios.

In genere el crédito al consumo se identifica a la operación (de préstamo) que proporciona a una persona -el consumidor-dinero o facilidades de pago, para la adquisición de bienes y servicios que se destinan al uso privado o particular. Es decir, bienes (prestaciones de dar) y servicios (prestaciones de hacer) que no se introducen en el proceso de producción ni se integran en las cadenas de distribución, ni se aplican al desarrollo de actividades estrictamente profesionales.

Jurídicamente, el crédito al consumo se traduce en una modalidad contractual, se habla de contrato de crédito, que se incardina entre los contratos de préstamo, en concreto en el préstamo mutuo (dinero /cosa fungible) y, en general, entre los que han venido a denominarse contratos de financiación. ${ }^{2}$

\section{La normativa comunitaria}

La tipificación y configuración jurídica autónoma del crédito al consumo como modalidad contractual del contrato de préstamo y en sede de este, del contrato de crédito, pese a que económicamente es una práctica habitual sobre todo a partir de la revolución industrial, es tardía. En el espacio europeo habrá que esperar al inicio de las políticas de protección al consumidor, la descripción y determinación de sus derechos, el desarrollo, en general, de acciones y la adopción de medidas de protección de diverso alcance, para que encuentre cabida entre ellas la primera normativa sobre esta modalidad crediticia. Reglamentación que se contiene en la Directiva 87/102/CEE/CEE del Consejo, de 22 de diciembre de 1986, relativa a la aproximación de las disposiciones legales, reglamentarias y administrativas de los Estados miembros en materia de crédito al consumo, aunque con anterioridad ya en el Programa preliminar de la Comunidad Económica Europea para una política de protección e información de los consumidores ${ }^{3}$ (1975) se establecia la prioridad de la armonización de las disposiciones reguladoras del crédito al consumo entre los Estados miembros; preferencia que siempre había formado parte de los objetivos de la política europea sobre consumo.

En la caracterización del contrato de crédito al consumo tiene particular importancia la Directiva 87/102/CEE pues no solo se adopta en ella una denominación (nomem) que contribuye a la identificación de la operación económica y del contrato a través del cual se regula, sino que aporta los rudimentos, datos mínimos de tipificación contractual (los índices de tipo) ${ }^{4} \mathrm{de}$ los que resulta su autonomía contractual.

A partir de esta Directiva jurídicamente se consagra un nuevo contrato, en realidad un sub tipo contractual que habrá de tener la misma denominación y contenido mínimo en todos los Estados europeos que formen parte de la Unión (en la actualidad), cuando la incorporen a su ordenamiento interno. Desde la perspectiva de los conceptos jurídicos relativos al contrato,

1 Vid. MARÍN LÓPEZ, Manuel Jesús, La compraventa financiada de bienes de consumo, Editorial Arazandi, Pamplona, 2000, pp. 33 y ss.

2 Aunque jurídicamente no exista, en si como tal categoría contractual ha devenido denominación usual en la doctrina.

3 Aprobado por la Resolución del Consejo de 14 de abril de 1975.

4 Respecto del concepto de índices de tipo me remito a GETE-ALONSO Y CALERA, María del Carmen, Estudios sobre el contrato, Capítulo II, La tipicidad contractual, Editorial Atelier, Barcelona, 2008, pp. 41 a 88. 
un término jurídico ${ }^{5}$ nuevo y un contrato en el que los datos de tipificación, y algunos (los mínimos) de su régimen, serán comunes. Recuérdese que la incorporación de la Directiva 87/102/ CEE no impedía que cada uno de los Estados miembros pudieran aumentar la protección y, en consecuencia, establecieran algunas reglas diferentes. ${ }^{6}$

De las diversas cuestiones y materias que podrían haberse regulado sobre el crédito al consumo ${ }^{7}$ aquella se ciñó, de ahí su importancia, al ámbito privado (jurídico económico). En concreto, parafraseando sus considerandos ${ }^{8}$ la finalidad de la normativa se dirigía a:

- "(...) la creación de un mercado común de crédito al consumo /que/ beneficiaría por igual a los prestamistas, a los fabricantes, a los mayoristas y minoristas así como a los proveedores de servicios".

- La protección del consumidor, en general, dotándole de información y de los medios para protegerse "contra las cláusulas abusivas del crédito", y

- La "armonización de las condiciones generales que regulan el crédito al consumo".

La Directiva fue modificada en dos ocasiones por la Directiva 90/88/CEE y la Directiva 98/7/ $\mathrm{CE}$, que incidieron, fundamentalmente en la fórmula matemática comunitaria para el cálculo del porcentaje anual de cargas financieras.

Casi diez años más tarde la nueva Directiva 2008/48/CEE/CE del Parlamento europeo y del Consejo $0^{9}$ relativa a los contratos de crédito al consumo, deroga la Directiva 87/102/CEE/ $\mathrm{CEE}$, introduce innovaciones de interés en los datos de tipificación del contrato y en el propio régimen del crédito e impone la obligación de incorporación de los mínimos. Frente a la anterior Directiva, las normas de la 2008/48/ CEE tienen carácter obligatorio porque las disposiciones de armonización que contiene no pueden soslayarse: "(...) los Estados miembros no podrán mantener o adoptar en su legislación nacional disposiciones diferentes de las que en ella se estipulan" (artículo 22.1). Y han de tomar "las medidas necesarias para garantizar que los consumidores no se vean privados de la protección que les otorga la presente Directiva (...)" (artículo 22.4). Es una Directiva de máximos, no de mínimos ${ }^{10}$ mediante la que se pretende (al igual que en la anterior pero ahora con más fuerza) la creación de un mercado único real regido por "unas normas comunitarias orientadas hacia el futuro, que puedan adaptarse a las futuras formas de crédito"11, en el que "(...) la armonización total es necesaria para garantizar que todos los consumidores de la Comunidad se beneficien de un nivel elevado y equivalente de protección de sus intereses."12

5 Se entiende por "término" la unidad léxica que designa una noción en un ámbito especializado determinado, que es la expresión lógica de un concepto, en este caso del concepto jurídico. El término no se forma siempre con una sola palabra sino que puede estar compuesto por más de una, ya que se trata de una expresión lógica, no gramatical.

6 El artículo 15 de la Directiva 87/102/CEE/CEE prevé expresamente: “La presente Directiva no impedirá que los Estados miembros conserven o adopten disposiciones más severas para la protección del consumidor, y que sean acordes con sus obligaciones en virtud del Tratado".

7 Los controles administrativos de la actividad de préstamo / crédito, requisitos de las personas legitimadas para actuar como prestamistas y de los intermediarios, transparencia y fiscalidad, etc.

8 Considerandos 4 y 5, principalmente. DOCE núm. L.42 de 12 de febrero de 1987, pp. 48-53.

9 DOCE, L. 133, 25 de mayo de 2008, pp. 66 a 92.

10 MARIN LÓPEZ, Manuel Jesús, La nueva regulación europea del crédito al consumo (Directiva 2008/48/CEE/CEE, de 23 de abril de 2008). En: www.uclm.es/cesco, Centro de Estudios de Consumo 2008. Sobre la Directiva nueva puede consultarse para una información general, SEGURA RODA, Isabel, La nueva Directiva sobre el crédito al consumo: objeto y ámbito de aplicación. En: Revista electrónica de Derecho del Consumo y de la Alimentación, No. 18, 2008. En: http:// aibadaredeco.googlepages.com, consultado en enero de 2009.

11 Considerando 7.

12 Considerando 9. 
Indica el Considerando 10 que las "definiciones que contiene la presente Directiva determinan el alcance de la armonización", entre las que se contienen las de los sujetos (partes) que intervienen en el contrato, la de otras personas, la del contrato de crédito, diversas modalidades de este y el contrato de crédito vinculado que delimitan, jurídicamente al contrato (contribuyen a su tipificación). "La obligación de los Estados miembros de aplicar las disposiciones de la presente Directiva deben limitarse - continúa diciendo-, por consiguiente, al ámbito de aplicación que dichas definiciones determinan".

La nueva presentación del contrato de crédito al consumo, que será ius commune para todo el espacio europeo es la que me ha motivado a estudiar este contrato, en particular a desentrañar los datos de su tipificación jurídica como contrato autónomo.

\section{La legislación española}

Hasta la incorporación al ordenamiento interno de la Directiva 87/102/CEE/CEE apenas existia una regulación propia sobre el crédito al consumo y diferenciada de las reglas generales sobre el contrato de préstamo del Código Civil (artículos 1740 y 1753 a 1757) o del Código de Comercio (artículos 311 a 324), y por supuesto de las generales de la obligación (artículos 1088 y siguientes del Código Civil). el cumplimiento de las obligaciones nacidas de aquellos contratos". económicos que con la venta a plazos". contrato de crédito al consumo.
Quien adquiría o contrataba un bien o servicio (consumidor-usuario) si no disponía de dinero debía acudir bien al préstamo, ya simple, ya garantizado (con fianza, prenda o hipoteca) o, en el caso de que se tratara de un contrato de compraventa podía pactar un aplazamiento del pago junto al pacto de reserva de dominio (que actúa como garantía del cobro). Las malas prácticas que se desarrollaron en los contratos con precio aplazado (cláusulas de pérdida de beneficio del plazo en los supuestos de pago parcial, sin precisar valores, recuperación del bien por el vendedor sin derecho a devolución de lo pagad, pacto comisorio, etc.) dieron paso a una normativa especifica sobre la venta a plazos: la Ley 50/1965, de 17 de julio, de Venta de Bienes Muebles a Plazos, norma que no solo se aplicaba a las ventas, pues comprendia todos los contratos dirigidos a financiar compra y en general todas las operaciones económicas ${ }^{13}$ que respondieran al mismo fin, de modo que, así se evitaba que la utilización de otro tipo contractual pudiera ser un fraude a la ley.

Aunque podría citarse como precedente remoto la Ley 26/1984, de 19 de julio, General para la Defensa de los Consumidores y Usuarios ${ }^{14}$ (en adelante LGDCU), en el ordenamiento jurídico español el camino hacia una legislación propia en esta materia, se inicia a partir de la Ley $7 / 1995$ de Crédito al Consumo (en adelante LCC), de 7 de marzo, mediante la que se incorpora aquella al ordenamiento interno y que ha sido objeto

13 Indicaba el artículo 1: "Es objeto de la presente Ley la regulación de las ventas a plazos de bienes muebles corporales no consumibles, de los préstamos destinados a facilitar su adquisición, y de las garantias que se constituyan para asegurar

Se agregaba en el artículo 2: "Por venta a plazos se entenderá, a efectos de esta Ley, el contrato mediante el cual el vendedor entrega al comprador una cosa mueble corporal y recibe de éste, en el mismo momento, una parte del precio, con la obligación de pagar el resto diferido en un periodo de tiempo superior a tres meses y en una serie de plazos que se determinarán en la forma que dispone el artículo 20. También se entenderán comprendidos en esta Ley los actos o contratos, cualquiera que sea su forma jurídica, mediante los cuales las partes se propongan conseguir los mismos fines

14 La Ley General para la Defensa de consumidores y Usuarios no es, en propiedad, un antecedente pues solo de manera tangencial (aunque no se ha desdeñar por la innovación que supuso en aquel momento) se refería al crédito al prohibir las condiciones abusivas. Lo que, de alguna manera se justifica por el carácter de la ley. La ínexistencia de referencia expresa, con todo, no significaba que sus normas no fueran aplicables al crédito sino sólo que no se recogían las particularidades de estos contratos. Por supuesto, entonces no se preveia la tipificación de un nuevo 
de modificación en varias ocasiones a fin de acomodarla a diversas Directivas, entre las que se incluyen las de la Directiva 87/102/CEE, y a la realidad económica y jurídica interna. ${ }^{15}$

Tres años más tarde una nueva Ley 28/98, de 13 de julio, de Venta a Plazos de Bienes Muebles (en adelante LVPBM) sustituye y deroga la Ley 50/1965, aunque mantiene gran parte de la redacción de los preceptos de esta y de su contenido que acomoda a la nueva realidad jurídica para evitar las disfunciones que se producían entre la Ley 50/1965 y la de Crédito al Consumo. La ley 28/1998 hace numerosas remisiones a la LCC e intenta la coordinación entre ambas con la finalidad de proteger al consumidor y de separar, técnicamente, los dos contratos: el de compraventa a plazos y el de crédito. Frente a los solapamientos que se habían producido "la presente Ley -se dice en la Exposición de Motivos- parte del criterio básico de remitir a la Ley de Crédito al Consumo las medidas que tengan como finalidad fundamental el incremento del nivel de protección al consumidor y de centrar en la Ley de venta a plazos la regulación del contrato de compraventa de bienes muebles". Previamente, Ley 7/1998, de 13 de abril, sobre condiciones generales de la contratación, modificó la LGDCU e introdujo importantes modificaciones en esta y un listado de condiciones generales consideradas abusivas, entre las que se incluían algunas relativas al crédito, en las que se consideraba la LCC.

A finales de 2007 se publica el Real Decreto Legislativo $1 / 2007$, de 16 de noviembre, por el que se aprueba el texto refundido de la Ley General para la Defensa de los Consumidores y Usuarios y otras leyes complementarias (en adelante TRLGDCU்). En este se introducen importantes innovaciones entre las que sobresalen las definiciones de las diferentes personas que pueden intervenir en la relación de consumo y sobre todo el Libro II en el que se regulan las relaciones jurídicas privadas: título I, contratos con los consumidores y usuarios; título II, el régimen jurídico de las condiciones generales y las cláusulas abusivas; título III, los contratos celebrados a distancia; título IV, los contratos celebrados fuera de establecimientos mercantiles; título $\mathrm{V}$, garantía y servicios postventa. Preceptos que son de aplicación, junto a la LCC al contrato que nos ocupa que, a diferencia de otros, no incorporó el Texto Refundido.

La nueva Directiva 2008/48/CEE/ obliga a que antes del 12 de mayo de 2010, los Estados miembros adopten y publiquen las disposiciones necesarias para dar cumplimiento a lo dispuesto en ella e informen inmediatamente a la Comisión. Las nuevas disposiciones, además, han de incluir una referencia a la Directiva o ir acompañadas de dicha referencia en su publicación oficial, para lo que los Estados miembros son libres de establecer cómo se hará. En todo caso, se produzca o no la incorporación en el tiempo indicado, las disposiciones de la Directiva son de obligada aplicación a partir de 12 de mayo de 2010 (artículo 27.1).

Será necesario, asi pues, ponerse manos a la obra a fin de acomodar la normativa existente a la nueva Directiva. El panorama que resulta, de la conjunción de las normas indicadas, lleva a analizarlas a fin de formular una propuesta doctrinal acerca del contrato de crédito al consumo que, si bien está en el acervo común jurídico debe reconsiderarse. En ningún momento se ha de perder de vista que solo el contrato de crédito que sea de consumo, a tenor de las normas,

15 Las modificaciones son las de la Ley 39/2002, de 28 de octubre, de transposición al ordenamiento jurídico español de diversas directivas comunitarias en materia de protección de los intereses de los consumidores y usuarios (BOE número 259, de 29-10-2002, pp. 37922-37933) por la que se modificó el artículo 18 y el Anexo y se añadió un artículo 20 y una disposición adicional única. Y la Ley 62/2003, de 30 de diciembre, de medidas fiscales, administrativas y del orden social (BOE número 313, de 31-12-2003, pp. 46874-46992) que modificó los artículos 2 (exclusiones del ámbito de la ley) y 15 (derechos ejercitables en los contratos vinculados) que obedeció, fundamentalmente, a los problemas que se suscitaron a raíz de los casos de cierres de academias de inglés (Opening (...)), cursos que estaban financiados mediante varías modalidades de crédito, algunas de consumo, otras a través de diversas operaciones contractuales. Se discutió, entonces acerca de los requisitos de la vinculación del contrato tal y como los recogía la ley española. 
es decir el tipo contractual tipificado, es el que entra en su ámbito, de manera que aquel en el que no concurran los datos estará sometido al régimen general, el del tipo base. De otra parte, interesa dejar en claro cuál es el régimen mínimo del contrato de crédito al consumo que se suma al régimen propio del tipo base, o de la operación que se reciba la calificación de ser crediticia.

\section{EL CONTRATO DE CRÉDITO AL CONSUMO: PRESUPUESTOS}

Punto de partida obligado para determinar qué se entienda cómo contrato de crédito al consumo, es el legal: las definiciones que acerca del mismo se hacen en las Directivas y en la legislación interna. De ellas se siguen no solo los datos (índices) de tipificación sino, como se apuntó, incluso el régimen.

\section{Las definiciones legales}

El artículo 1.2 c de la Directiva 87/102/CEE definía el contrato de crédito como "aquél mediante el cual un prestamista concede o promete conce- der a un consumidor un crédito bajo la forma de pago aplazado, préstamo u cualquier otra facilidad de pago. A los efectos de la presente Directiva, no se considerarán contratos de crédito los que consistan en la prestación de servicios - privados o públicos- con carácter de continuidad y en los que asista al consumidor el derecho de pagar tales servicios a plazos durante el período de su duración". Lo que completaba, el artículo $2^{16}$ con un listado de contratos que se excluían total o parcialmente de su ámbito, en síntesis los criterios considerados eran económicos (el carácter gratuito, que no llegaran o superaran una determinada suma dineraria); la duración del contrato (los de corta duración), los tipos contractuales que comportaran la adquisición presente o futura de la propiedad inmobiliaria y determinadas formas crediticias bancarias.

El artículo 3 c) de la Directiva 2008/48/CEE, define el contrato de crédito como aquel "contrato mediante el cual un prestamista concede o se compromete a conceder a un consumidor un crédito en forma de pago aplazado, préstamo u otra facilidad de pago similar, exceptuados los contratos para la prestación continuada

16 Artículo 2:"1. La presente Directiva no se aplicará a: a) los contratos de crédito o de promesa de crédito: - destinados fundamentalmente a la adquisición o conservación de derechos de propiedad sobre terrenos o inmuebles construidos o en proyecto;

- destinados a la renovación o mejora de inmuebles;

b) los contratos de arrendamiento, excepto cuando éstos prevean que el titulo de propiedad pase en última instancia al arrendatario;

c) los créditos concedidos o puestos a disposición sin pago de intereses o cualquier otro tipo de cargas;

d) los contratos de crédito que no devenguen interés, siempre que el consumidor esté de acuerdo en reembolsar el crédito en un solo pago;

e) los créditos en forma de anticipos en una cuenta corriente, concedidos por una entidad de crédito o una entidad financiera, diferentes de una cuenta de tarjeta de crédito; no obstante lo dispuesto en el artículo 6 se aplicará a tales créditos; f) los contratos de crédito cuyo importe sea inferior a 200 ECUS o superior a 20000 ECUS;

g) los contratos de crédito en virtud de los cuales se exija al consumidor reembolsar el crédito:

- bien dentro de un plazo que no rebase los tres meses;

- bien mediante cuatro pagos, como máximo, dentro de un plazo que no rebase los doce meses.

2. Los Estados miembros podrán, previa consulta a la Comisión, eximir de la aplicación de la presente Directiva a determinadas clases de crédito que cumplan los siguientes requisitos:

- que hayan sido concedidos a tipos de interés inferiores a los practicados en el mercado, y - que no se ofrecieren al público en general.

3. Las disposiciones del artículo 4 y de los artículos 6 a 12 no se aplicarán a los contratos de crédito o de promesa de crédito con garantía de hipoteca inmobiliaria, siempre y cuando éstos no hayan quedado ya excluidos de la Directiva en virtud de la letra a) del apartado 1.

4. Los Estados miembros podrán exceptuar de las disposiciones de los artículos 6 a 12 a los contratos de crédito en forma de documento auténtico autorizado por notario o juez". 
de servicios o para el suministro de bienes de un mismo tipo en el marco de los cuales el consumidor paga por tales bienes o servicios de manera escalonada mientras dure la prestación". El artículo $2^{17}$, paralelo al artículo 2 de la anterior Directiva, añade, a la exclusión que se contiene en la definición, un listado de contratos en el que se mantienen los mismos criterios que en aquella, pero en el que se especifican determinados supuestos sobre los que se habian planteado discusiones. En todo caso, la mayor concreción supone una delimitación más exacta del contrato de crédito al consumo que se recoge.

La Ley española 7/1995 en su artículo 1.1 (ámbito de aplicación) en la transposición al ordenamiento interno del precepto incorporó en la definición la calificación de las partes que intervienèn en el contrato: "1. La presente Ley se aplicará a los contratos en que una persona física o jurídica en el ejercicio de su actividad, profesión $u$ oficio, en adelante empresario, concede o se compromete a conceder a un consumidor un crédito bajo la forma de pago aplazado, préstamo, apertura de crédito o cualquier medio equivalente de financiación, para satisfacer necesidades personales al margen de su actividad empresarial o profesional". A lo que se agrega (en el apartado 3 ), que no tienen la consideración de "contratos de créditos los que consistan en la prestación de servicios, privados o públicos, con carácter de continuidad, y en los que asista al consumidor el derecho a pagar tales servicios a plazos durante el período de su duración". $Y$ en su artículo $2^{18}$ enumeró los diversos contratos y operaciones que se exceptúan de la aplicación total, bien parcial

17 Artículo 2 (Ámbito de aplicación)

"1. La presente Directiva se aplicará a los contratos de crédito.

2. La presente Directiva no se aplicará a:

a) los contratos de crédito garantizados por una hipoteca o por otra garantía comparable comúnmente utilizada en un Estado miembro sobre bienes inmuebles o garantizados por un derecho relativo a un bien inmueble;

b) los contratos de crédito cuya finalidad sea adquirir o conservar derechos de propiedad sobre terrenos o edificios construidos o por construir;

c) los contratos de crédito cuyo importe total sea inferior a 200 EUR o superior a 75 O00 EUR;

d) los contratos de arrendamiento o de arrendamiento financiero en los que no se establezca una obligación de compra del objeto del contrato, ni en el propio contrato ni en otro contrato aparte; se considerará que existe obligación si el prestamista asi lo ha decidido unilateralmente;

e) los contratos de crédito concedidos en forma de facilidad de descubierto y que tengan que reembolsarse en el plazo de un mes;

f) los contratos de crédito concedidos libres de intereses y sin ningún otro tipo de gastos, y los contratos de crédito en virtud de los cuales el crédito deba ser reembolsado en el plazo de tres meses y por los que solo se deban pagar unos gastos mínimos;

g) los contratos de crédito concedidos por un empresario a sus empleados a título subsidiario y sin intereses o cuyas tasas anuales equivalentes sean inferiores a las del mercado, y que no se ofrezcan al público en general; los contratos de crédito celebrados con empresas de inversión en el sentido del articulo 4, apartado 1, de la Directiva 2004/39/CE del Parlamento Europeo y del Consejo, de 21 de abril de 2004, relativa a los mercados de instrumentos financieros, o con entidades de crédito en el sentido del artículo 4 de la Directiva 2006/48/CE, a efectos de que un inversor pueda realizar una operación en relación con uno o más de los instrumentos enumerados en la sección C del anexo l de la Directiva 2004/39/CE, Cuando la empresa de inversión o la entidad de crédito que concede el crédito participe en la operación;

i) los contratos de crédito que son el resultado de un acuerdo alcanzado en los tribunales o ante cualquier otra autoridad pública;

j) los contratos de crédito relativos al pago aplazado, sin gastos, de una deuda existente;

k) los contratos de crédito para cuya celebración se pide al consumidor que entregue un bien al prestamista como garantía de seguridad y en los que la responsabilidad del consumidor está estrictamente limitada a dicho bien;

1) los contratos de crédito relativos a préstamos concedidos a un público restringido, en virtud de una disposición legal con un objetivo de interés general, y a un tipo de interés inferior al habitualmente propuesto en el mercado o sin interés o en condiciones que son más favorables para el consumidor que las habituales en el mercado y a un tipo de interés no superior al habitualmente propuesto en el mercado."

18 Artículo 2. Exclusiones del ámbito de la Ley

"1. Quedan excluidos de la presente Ley:

a) Los contratos en los que el importe del crédito sea inferior a 150 euros. A los superiores a 20.000 euros tan sólo les será

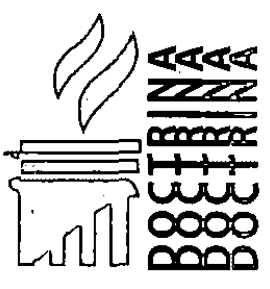


de la normativa sobre el crédito al consumo; se añadían algunas precisiones, respecto de las reglas de la Directiva $87 / 102 /$ CEE, pero los criterios eran los mismos.

La Directiva 2008/48/CEE, frente a la anterior, no modifica sustancialmente la definición del contrato de crédito al consumo, pero introduce matizaciones de interés, en la línea, como apunta en sus Considerandos ${ }^{19}$ de "facilitar la emergencia de un mercado interior con un funcionamiento satisfactorio en el ámbito del crédito al consumo" y para dar cabida a las diversas formas de crédito tanto las actuales como las que se produzcan en el futuro.

A las definiciones ya acuñadas la nueva Directiva agrega la de otras operaciones crediticias y la del contrato de crédito vinculado, para comprender la realidad práctica que se ha desarrollado en torno a estos contratos $y$, seguramente, para acabar con las dudas que se habian suscitado en estos conceptos.

A tenor del artículo $3 n$, se considera contrato de crédito vinculado: "un contrato de crédito en el que:

i) el contrato en cuestión sirve exclusivamente para financiar un contrato relativo al suministro de bienes específicos o a la prestación de servicios específicos, y

i) los dos contratos constituyen una unidad comercial desde un punto de vista objetivo; se considerará que existe una unidad comercial cuando el proveedor del bien o el suministrador del servicio financian el crédito al consumo o, en el caso de que este sea financiado por un tercero, cuando el prestamista se sirve de la intervención del proveedor del bien o el suministrador del servicio en la preparación o celebración del contrato de crédito, o cuando los bienes específicos o la prestación de un servicio específico vienen expresamente indicados en el contrato de crédito."

Separadamente del contrato de crédito al consumo se define la posibilidad de descubierto y el rebasamiento. Se entiende por posibilidad de descubierto el "contrato de crédito explícito mediante el cual un prestamista pone a disposición de un consumidor fondos que superen el saldo en la cuenta corriente del consumidor" y por rebasamiento: "el descubierto aceptado tácitamente mediante el cual un prestamista pone a disposición de un consumidor fondos que superen el saldo de la cuenta corriente del consumidor o la posibilidad de descubierto convenida" (artículo 3, d y e).

Finalmente, tanto en la Directiva 87/102/CEE como en la Directiva 2008/48/CEE, y la ley española $7 / 1995$ describen a quienes intervienen como partes en el contrato: prestamista y consumidor (artículos 3, a y b de ambas). La norma

de aplicación lo dispuesto en el capítulo III de esta Ley. A los efectos anteriores, se entenderá como única la cuantía de un mismo crédito, aunque aparezca distribuida en contratos diferentes, celebrados entre las mismas partes y para la adquisición de un mismo bien o servicio, aun cuando los créditos hayan sido concedidos por diferentes miembros de una agrupación, tenga ésta o no personalidad juridica.

b) Aquellos en los que se pacte que el consumidor reembolse el crédito, bien dentro de un único plazo que no rebase los tres meses, bien en cuatro plazos, como máximo, dentro de un periodo que no supere los doce meses.

c) Los créditos en cuenta corriente, concedidos por una entidad de crédito, que no constituyan cuentas de tarjeta de crédito. Tales operaciones quedarán, no obstante, sometidas a lo dispuesto en el artículo 19 de la presente Ley.

d) Los contratos en los que el crédito concedido sea gratuito, o en los que, sin fijarse interés, el consumidor se obligue a reembolsar de una sola vez un importe determinado superior al del crédito concedido.

En el caso de servicios de trato sucesivo y prestación continuada, no se considerarán gratuitos aquellos créditos en los que, aunque la tasa anual equivalente, definida en los términos del articulo 18 de esta Ley, sea igual a cero, su concesión conlleve algún tipo de retribución por parte del proveedor de los servicios al empresario prestamista.

2. Las disposiciones de los artículos 6 a 14 y 19 no se aplicarán a los contratos de crédito garantizados con hipoteca inmobiliaria".

19 Considerando 7. 
actual, si se compara con la anterior, mantiene el concepto de consumidor para la persona física que actúa como no profesional o comercial ${ }^{20}$, y el de prestamista como "la persona física o jurídica que concede o se compromete a conceder un crédito en el ejercicio de su actividad comercial o profesional" (se elimina la referencia a "cualquier agrupación de personas" que se hacía en la Directiva 87/102/CEE).

Este criterio es el que acogía la Ley $7 / 1995^{21}$ LCC, para definir al consumidor, pese a que, en ese momento la Ley 26/1984, LGDCU mantenía el concepto general de consumidor como destinatario final ${ }^{22}$; noción de consumidor que en la legislación española abarcaba, a diferencia de las Directivas, a la persona física y a la persona jurídica. El Texto refundido de la-Ley General para la Defensa de los Consumidores y Usuarios (RD 1/2007, TRLGDCU) hoy vigente modificó el concepto de consumidor/destinatario final para adaptarlo al consumidor no profesional que, en la actualidad, es el que adoptan en las Directivas europeas sobre consumo ${ }^{23}$ y mantuvo que se aplicaba tanto a la persona física como a la jurídica. Nada se decía acerca del prestamista a quien la ley española calificaba como"empresario" en la definición general del contrato.

La cualidad de los sujetos que intervienen, el destino y la concreta modalidad crediticia (objeto), con más o menos coincidencias entre ellas, son los datos de los que se sirven las normas para tipificar el crédito al consumo como un contrato o contratos autónomos. A ello se ha de añadir el contenido mínimo del contrato (derechos y deberes de las partes), que conforman su régimen jurídico.

Las precisiones, en verdad innovaciones de la Directiva 2008/48/CEE, en las que se han recogido nuevos instrumentos del crédito y formas de uso, suponen una ampliación importante ${ }^{24}$ que, junto al carácter obligatorio mencionado,

20 "Al margen de su actividad comercial o profesional" indica el artículo 3.b de la Directiva 200/48. La anterior Directiva 87/102/CEE estaba redactada de otra forma pero el significado era el mismo.

21 El apartado 2 del artículo 1 señala: "A los efectos de esta Ley se entenderá por consumidor a la persona fisica que, en las relaciones contractuales que en ella se regulan, actúa con un propósito ajeno a su actividad empresarial o profesional".

22 En los artículos 1.2 y 1.3 (hoy derogados) se decía:

"2. A los efectos de esta Ley, son consumidores o usuarios las personas fisicas o juridicas que adquieren, utilizan o disfrutan como destinatarios finales, bienes muebles o inmuebles, productos, servicios, actividades o funciones, cualquiera que sea la naturaleza pública o privada, individual o colectiva de quienes los producen, facilitan, suministran o expiden. 3. No tendrán la consideración de consumidores o usuarios quienes sin constituirse en destinatarios finales, adquieran, almacenen, utilicen o consuman bienes o servicios, con el fin de integrarlos en procesos de producción, transformación, comercialización o prestación a terceros".

23 Artículo 3. Concepto general de consumidor y de usuario.

"A efectos de esta norma y sin perjuicio de lo dispuesto expresamente en sus libros tercero y cuarto, son consumidores o usuarios las personas físicas o jurídicas que actúan en un ámbito ajeno a una actividad empresarial o profesional".

Artículo 4. Concepto de empresario.

"A efectos de lo dispuesto en esta norma, se considera empresario a toda persona física o jurídica que actúa en el marco de su actividad empresarial o profesional, ya sea pública o privada".

24 Explican las razones de la modificación los Considerandos. Los primeros nos dan las pautas generales que, después se exponen en el resto.

"(2) La Comisión presentó en 1995 un informe sobre la aplicación de la Directiva 87/102/CEE/CEE y realizó una amplia consulta de las partes interesadas. En 1997, la Comisión presentó un informe resumido sobre las reacciones al informe de 1995. En 1996 se elaboró un segundo informe sobre la aplicación de la Directiva 87/102/CEE/CEE.

(3) De los informes y las consultas se desprendía que aún existian diferencias sustanciales entre las legislaciones de los Estados miembros en el ámbito del crédito a las personas fisicas en general y del crédito al consumo en particular. En efecto, el análisis de las leyes nacionales que incorporan la Directiva 87/102/CEE/CEE pone de manifiesto que los Estados miembros utilizan otros mecanismos de protección del consumidor además de la Directiva 87/102/CEE/CEE, debido a las diferencias existentes en las situaciones juridicas o económicas nacionales. 
presentan un contrato del crédito al consumo unificado del que vale la pena desentrañar los datos de tipificación. En las líneas que siguen, por lo tanto, ceñiré el estudio en los preceptos de la Directiva 2008/48/CEE. Téngase presente la necesaria adaptación que ha de hacerse a esta normativa.

\section{Los datos legales previos}

De la lectura de los textos legales, junto al acervo jurídico ya existente en esta materia, se siguen una serie de datos previos junto a los propios índices de tipificación del contrato, que conviene destacar:

El contrato de crédito al consumo, en primer lugar, se delimita por un ámbito concreto de la realidad económica en la que se inserta ${ }^{25}$ : la aplicación/destinación del crédito a la adquisición de bienes y servicios por una persona que actúa con una finalidad ajena a la profesión o actividad comercial (el consumidor) y la concesión del crédito por una persona profesional: el prestamista. De modo que:

1.- La caracterización jurídica de este contrato de crédito en particular (sub tipo o modalidad contractual) depende de su pertenencia a la normativa de consumo. Recuérdese que es contrato de crédito al consumo.

2.- De ahí las definiciones de consumidor y de prestamista. Dicho de otra manera, en el contrato de crédito al consumo necesariamente una parte ha de tener la calificación de consumidor y otra de prestamista: "contrato mediante el cual un prestamista concede o se compromete a conceder a un consumidor un crédito" (artículo $3 \mathrm{c}$ ). No obstante, la cualidad de las partes contratantes no es un criterio cualitativo (subjetivo) específico de este contrato ${ }^{26}$, pues es una exigencia común a todos los contratos o, mejor a las relaciones contractuales de consumo. Aunque no existe una Directiva a la que pueda calificarse como genérica, como ejemplo de descripción del posible "contrato de consumo" puede traerse a colación el artículo $59 \mathrm{del}$ TRLGCU, cuyo apartado 1 indica una obviedad que, quizá era necesaria para fijar los conceptos: "Son contratos con consumidores y usuarios los realizados entre un consumidor o un usuario $y$ un empresario".

El contrato de crédito al consumo es, valga la perogrullada, un contrato realizado entre un consumidor y un usuario y un prestamista/empresario. La única concreción, en las Directivas, se hacia y mantiene, solo para una de las partes contratantes, a la que se denomina prestamista, de los posibles empresarios solo los que se dediquen a la actividad crédito/financiación. En esto contrasta la Ley $7 / 1995$ LCC española que adoptó el término amplio de empresario (que utiliza también el TRLGDCU). En todo caso, la descripción de la Directiva de la actividad nos conduce al tipo contractual en el que se inserta el crédito. Los requisitos que se exigen a las partes son presupuestos del contrato (calidad de consumidor/prestamista).

3.- El entronque con la normativa de consumo implica, por sí, la asignación de un destino determinado. La aplicación del crédito a una relación

(4) La situación de hecho y de derecho resultante de estas disparidades nacionales produce en algunos casos distorsiones de la competencia entre prestamistas dentro de la Comunidad y entorpece el funcionamiento del mercado interior cuando las disposiciones obligatorias adoptadas por los Estados miembros son más restrictivas (...)

(5) En los últimos años han cambiado considerablemente los tipos de crédito ofrecidos a los consumidores y utilizados por ellos. Han aparecido nuevos instrumentos de crédito y su uso sigue desarrollándose. Conviene, pues, modificar las disposiciones vigentes y, en caso necesario, ampliar su ámbito de aplicación".

25 Como el instrumento jurídico adecuado a través del que se lleva a cabo el intercambio de bienes y servicios que es el contrato, en este caso, el contrato de crédito al consumo.

26 Como a veces se ha presentado por la doctrina. Vid, RIVERO ALEMÁN, Santiago, Crédito, Consumo y Comercio Electrónico, Editorial Aranzadi, Pamplona, 2002, pp. 198 y ss. 
contractual, rectius, a la financiación, in genere, de una relación contractual de adquisición de un bien o de un servicio para uso ajeno al profesional, relación de consumo, es la razón que justifica la específica regulación (reglas propias). Unas normas que actúan en todas las fases del contrato, desde su formación hasta su cumplimiento.

El crédito al consumo tiene una finalidad o destino que se manifiesta en una relación contractual, ya previa, ya posterior, vinculada o no, pero siempre prevista. La previsión necesaria de la adquisición que facilita el crédito, rectius de la relación contractual mediante que es el título (jurídico) de la adquisición, es inherente al concepto y se diferencia netamente de la vinculación que es un plus, y como tal al que se agrega una regulación particular.

Además, en la delimitación legal por la que se ha optado, el empleo/aplicación del crédito y la existencia de nexo jurídico (vinculación) son datos a partir de los que se discriminan regimenes diferenciados del contrato de crédito ordinario.

4.- El contrato de crédito al consumo, es autónomo y principal pero las operaciones económicas que se "visten" en la Directiva permiten distinguir entre:

a.- El tipo contractual autónomo de contrato de crédito al consumo. Existe una definición genérica de contrato de crédito al consumo que se aplica a todos los que se incluyan en el supuesto de hecho delimitado. Un tipo contractual genérico en el que se comprenden las exclusiones (los contratos que se relegan a las reglas ordinarias de derecho privado) para aprehender la noción del tipo contractual.

b.- El tipo contractual contrato de crédito al consumo vinculado, en el que el índice de tipificación viene dado por la exigencia de un plus de dependencia jurídica entre el título adquisitivo y el crédito al consumo. Un plus que, como es sabido, hoy en día, a diferencia de la Directiva derogada, está definido en la ley por las notas de exclusividad en la financiación de determinados bienes y la existencia de una unidad comercial objetiva (artículo 3. n, Directiva 2008/48/CEE). $Y$ del que deriva, como es suficientemente conocido, un régimen especial, separado del resto de los demás contratos.

c.- Contratos de crédito al consumo con limitaciones del régimen. Es decir a los que no se aplican todos los preceptos que se previenen para este contrato, el que podría calificarse como régimen ordinario del crédito al consumo. Corresponden a esta modalidad contractual de crédito el supuesto de concesión a través de la posibilidad de descubierto (crédito explicito) y de rebasamiento (descubierto aceptado tácitamente) (artículo 2.3 y 4 Directiva 2008/48/CEE). ${ }^{27}$

d.- Tipos contractuales de crédito al consumo, en verdad, modalidades de contrato de crédito que, en inicio, están en la lista de los contratos excluidos, pero para los que los Estados miembros podrán disponer, siempre que cumplan con los requisitos que se imponen, la aplicabilidad de ciertos preceptos que prevé la norma. Son los supuestos de los apartados 5 y 6 del artículo $2^{28}$ de la Directiva 2008/48/CEE.

27 En estos se dice textualmente:

"3. En el caso de los contratos en los que el crédito se conceda en forma de posibilidad de descubierto y que deban reembolsarse previa petición o en el plazo de tres meses, solo serán aplicables los artículos 1 a 3, el artículo 4, apartado 1, el artículo 4, apartado 2, letras a) a c), el artículo 4, apartado 4, los artículos 6 a 9, el artículo 10, apartado 1, el artículo 10, apartado 4, el artículo 10, apartado 5, los artículos 12, 15 y 17 y los articulos 19 a 32.

4. En el caso de los contratos de crédito en forma de rebasamiento, solo serán aplicables los artículos 1 a 3, 18, 20 y 22 a 32".

28 El contenido de los apartados 5 y 6 es el siguiente:

"Los Estados miembros podrán disponer que sólo sean aplicables los artículos 1 a 4, los artículos 6, 7 y 9 , el artículo 10 , apartado 1, el artículo 10, apartado 2, letras a) a h) y l), el artículo 10, apartado 4, y los artículos 11,13 y 16 a 32 , a los contratos de crédito celebrados por una organización que:

a) se haya creado para el beneficio mutuo de sus miembros; 
5.- Finalmente, aunque parezca una obviedad, de los diferentes tipos contractuales, el de consumo se nomina como contrato de crédito, y la otra parte contractual como prestamista, de donde se asigna su pertenencia a una "familia contractual" determinada: la de los contratos que, en la tradición romanista del civil law, se incardinan en la causa credendi, y que como tipo contractual pertenecen al préstamo mutuo. Es esta asignación la primera a tener en cuenta pues el contrato de crédito al consumo, como es sabido, es un subtipo o modalidad del aquel ${ }^{29}$, tipificación que da lugar a un tipo contractual autónomo e independiente.

Del análisis detenido de la normativa (la Directiva $2008 / 48 / C E E$ ) se sigue lo que podría calificarse como régimen general u ordinario del contrato de crédito al consumo y diversas modalidades que se aíslan a partir de datos concretos que determinan ya la aplicación de un régimen especial, ya la exclusión de normas, e incluso la extensión a créditos que, en inicio, se excluyen.

Interesa, ahora, aislar los datos, índices de tipo, que tipifican a este contrato ya considerado entre los contratos crediticios. ${ }^{30}$

\section{CONTRATO DE PRÉSTAMO / CONTRATO DE CRÉDITO}

Es doctrina prácticamente indiscutida que, desde el punto de vista jurídico el contrato de crédito al consumo se incardina en el tipo contractual codificado de préstamo mutuo, si bien difiere de este en determinados datos que explican

b) no genere beneficios a personas distintas de los miembros;

c) persiga un objetivo social previsto por la legislación nacional;

d) reciba y gestione únicamente el ahorro de sus miembros y les facilite fuentes de crédito, y

e) proporcione el crédito a una tasa anual equivalente inferior al propuesto habitualmente en el mercado o sujeto a un limite máximo establecido por el Derecho interno, y en la que la condición de miembro esté restringida a las personas que residan o trabajen en un lugar especifico o a los empleados en activo y jubilados de un empleador concreto, o a las personas que reúnan otros requisitos establecidos por el Derecho interno como condición para que exista un vínculo común entre los miembros.

Los Estados miembros podrán eximir de la aplicación de la Directiva a los contratos de crédito celebrados por una organización de este tipo cuando el valor total de todos los contratos de crédito suscritos por la organización sea insignificante en relación con el valor total de todos los contratos de crédito suscritos en el Estado miembro en el que esté establecida la organización y el valor total de todos los contratos de crédito suscritos en el Estado miembro por organizaciones de este tipo sea inferior al $1 \%$ del valor total de todos los contratos de crédito suscritos en ese Estado miembro.

Los Estados miembros examinarán anualmente si se siguen dando las condiciones para conceder este tipo de exención y tomarán medidas para suprimir la exención cuando consideren que han dejado de cumplirse dichas condiciones.

6. Los Estados miembros podrán determinar que solo sean aplicables los artículos 1 a 4, los artículos 6, 7 y 9 , el artículo 10 , apartado 1, el artículo 10, apartado 2, letras a) a i), 1) y r), el articulo 10, apartado 4, los artículos 11, 13 y 16 y los artículos 18 a 32 a los contratos de crédito que prevean que el prestamista y el consumidor pueden establecer acuerdos relativos al pago aplazado o los métodos de reembolso cuando el consumidor ya se encuentre en situación de falta de pago del contrato de crédito inicial, siempre que:

a) tales acuerdos puedan evitar la posibilidad de actuaciones judiciales relativas al impago, y

b) el consumidor no se vea sometido a condiciones menos favorables que las establecidas en el contrato de crédito inicial.

Sin embargo, si el contrato entra dentro del ámbito de aplicación del apartado 3, solo serán aplicables las disposiciones previstas en dicho apartado".

29 Calificación que no ha sido discutida por la doctrina que ha estudiado el crédito al consumo. Vid, la referencia bibliográfica de la doctrina española, a la que me remito, de MARÍN LÓPEZ, Op. Cit., Compraventa financiada, en especial pp. 136 y 137, nota 39.

30 "Todo indice de tipo es un dato que se predica de alguno de los elementos del contrato y que propicia la diversificación entre tipos contractuales distintos (compraventa, arrendamiento, permuta (...))", GETE-ALONSO Y CALERA, María del Carmen, Op. Cit. Estudios sobre el contrato, pp. 66. 
el régimen propio. Datos que son los que han propiciado una tipificación autónoma.

\section{El préstamo mutuo codificado}

El tipo contractual codificado, en general, en los cuerpos legales de los Estados miembros de la Unión Europea, ya sea en el Código Civil o en el Código de Comercio (en aquellos en los que se distingue entre el préstamo civil y el préstamo mercantil) en el que se comprende el contrato es el simple préstamo o mutuo, también denominado préstamo de consumo. ${ }^{31}$ Contrato que, junto al comodato (el préstamo de cosa no fungible) es un subtipo del contrato de préstamo.

En el Código Civil español este contrato se define como aquel en el que una de las partes (mutuante - prestamista) entrega a la otra ${ }^{32}$ (mutuatario-prestatario) dinero $u$ otra cosa fungible ${ }^{33}$ de la que adquiere su propiedad con la obligación de devolver otro tanto de la misma especie y calidad (artículos 1740 y 1753 del Código Civil). A lo que, para su calificación mercantil el Código de Comercio (artículo 311) agrega que alguno de los contratantes sea co- merciante y que las cosas prestadas se destinen a actos de comercio. ${ }^{34}$

Conforme a la tradición romanista, pese a que la codificación de los contratos y la creación del tipo básico del contrato comportó la desaparición de las causas civilis obligand $i^{35}$ y con ello de la causa real (datio o do de presente), en la descripción del tipo contractual se mantuvo la referencia al desplazamiento posesorio del objeto del contrato (dinero u otra cosa fungible). De esta descripción, como es suficientemente conocido se ha derivado la clasificación entre los contratos consensuales y los contratos reales, en el seno de la que se sitúan el mutuo, el comodato, junto al contrato de depósito y el de prenda sin desplazamiento.

Según la caracterización más tradicional que el contrato de préstamo mutuo sea un contrato real significa que no es perfecto jurídicamente, no existe vinculación entre las partes, hasta que no tiene lugar el desplazamiento posesorio (entrega) de su objeto al prestatario, de manera que el contrato empieza a producir el efecto vinculación y el obligatorio a partir de la

31 Vid, en general, COCA PAYERAS, Miguel, Voz: Mutuo (Derecho Civil). En: Enciclopedia Jurídica Básica, Tomo III, Ed Civitas, Madrid, 1995.

32 El artículo 1892 del Code lo define de forma similar: "Le prêt de consommation est un contrat par lequel l'une des parties livre à l'autre une certaine quantité de choses qui se consomment par l'usage, à la charge par cette dernière de lui en rendre autant de même espèce et qualité". Se agrega en el artículo 1893 que "Par l'effet de ce prêt, l'emprunteur devient le propriétaire de la chose prêtée ; et c'est pour lui qu'elle périt, de quelque manière que cette perte arrive".

33 En el Codice Civili italiano se define, también de forma similar, al mutuo en el artículo 1813 (Nozione) como "II mutuo è il contratto col quale una parte consegna all'altra una determinata quantità di danaro o di altre cose fungibili, e l'altra si obbliga a restituire altrettante cose della stessa specie e qualità". Y en el artículo 1814 (Trasferimento della proprietà) "Le cose date a mutuo passano in proprietà del mutuatario". Además, en este Código existe una norma particular para la promesa de mutuo, artículo 1822 ("Chi ha promesso di dare a mutuo può rifiutare l'adempimento della sua obbligazione, se le condizioni patrimoniali dell'altro contraente sono divenute tali da rendere notevolmente difficile la restituzione, e non gli sono offerte idonee garanzie").

34 En el Código Civil de Perú se describe el contrato en el artículo 1648 (Definición): "Por el mutuo, el mutuante se obliga a entregar al mutuatario una determinada cantidad de dinero o de bienes consumibles, a cambio de que se le devuelvan otros de la misma especie, calidad o cantidad" y en el artículo 1654 (Efecto de la entrega), se indica que "Con la entrega del bien mutuado se desplaza la propiedad al mutuatario y desde este instante le corresponde la mejora, el deterioro o destrucción que sobrevengan".

Como se observa, pese a la influencia romanista, en este Código se adopta un concepto de mutuo consensual que se acomoda mejor a la realidad actual del mercado crediticio.

35 Para una explicación de la formación del concepto de contrato que se recoge en los Códigos Civiles me remito a GETE-ALONSO Y CALERA, María del Carmen, Estructura y Función del tipo contractual, Editorial Bosch S.A, Barcelona, 1979. 
misma. Así que el mero acuerdo consensual se reconduce a lo que se denomina promesa de contrato (o contrato preparatorio), la fórmula consensual del mismo. En mi opinión, lo que dejé explicado con más amplitud en otro estudio que no es ahora el momento oportuno de reitera $r^{36}$, la entrega de la cosa, que forma parte de la definición de este contrato no implica ni quita fuerza al consentimiento (acuerdo de voluntades sobre un objeto común) que forma y perfecciona el contrato y a partir del cual, existe a la vida jurídica (pues cuando se completa la formación tiene lugar la perfección). El contrato de préstamo mutuo existe en el momento en que las partes se ponen de acuerdo sobre el objeto y la causa del contrato (dinero-cosa fungible, causa credendi); o sea desde el consentimiento y a partir de este quedan vinculadas entre si jurídicamente. Cuestión diferente es el momento en que se inicia la producción de los efectos típicos del mismo ("desde entonces obligan" artículo 1258 del Código Civil).

Puesto que la opción por la que se decantaron, en general, los codificadores fue la de mantener como obligación típica del contrato de préstamo mutuo el reintegro (devolución) del tantundem (otro tanto de la misma especie y calidad), dada su naturaleza -no puede existir hasta que no consta el desplazamiento posesorio- a uno de los elementos del contrato: el consentimiento, se le agregó, al tipificar, un dato jurídico: la entrega. Dato que, en la terminología de la tipicidad contractual, es un indice de tipo general. Los índices generales son aquellos datos juridicos que se predican de los elementos del contrato, cuya presencia determina una tipificación contractual y una regulación unitaria y especifica. ${ }^{37}$

Para el caso que nos ocupa, la caracterización de la entrega de la cosa como un índice de tipo general significa, al ser un dato de tipificación, que los acuerdos contractuales (consentimientos obligatorios) puramente consensuales son subtipos del préstamo mutuo, que es lo que acontece, precisamente, en el contrato de crédito al consumo, que, durante un cierto tiempo era un contrato atípico. $Y$ que el contrato de mutuo es unilateral, pues solo existe obligación para el prestatario, frente a la bilateralidad del contrato de crédito. Volveremos después, cuando expliquemos los datos de este contrato.

Un nuevo dato jurídico de tipificación, por lo tanto índice general, es el que se predica del objeto del contrato: dinero o cosa fungible. Dato que coincide con alguna de las formas del crédito al consumo ya directamente, ya indirectamente. Conviene que lo retengamos pues permite no solo reconducir el contrato de crédito al consumo al préstamo simple, sino su diferenciación del contrato de comodato cuyas reglas no son de aplicación. Asimismo, otro indice general es la causa que cuando es contrato civil, es gratuita, salvo que se pacten intereses $y$, si es mercantil siempre es oneroso; aunque la causa de la entrega (traditio: transmisión de la propiedad) sea la causa credendi.

En el préstamo simple, al menos expresamente, no se menciona ${ }^{38}$ la duración, el tiempo en el que el prestatario está en poder de la suma de dinero o de las cosas fungibles, que otorga valor económico y jurídico al contrato. No obstante, este es un dato importante que está implícito en el contrato codificado y que se explicita en el contrato de crédito al consumo que estudiamos.

\section{El contrato de crédito}

Abordaremos primero el contrato de crédito en general, su delimitación (tipificación) jurídica

36 GETE-ALONSO Y CALERA, Maria del Carmen, Op. Cit., Estructura y Función, pp. 240 a 264.

37 GETE-ALONSO Y CALERA, María del Carmen, Op. Cit., Estudios sobre el contrato, pp. 66 a 68. "Añadir o sumar datos jurídicos, cuando se tipifica, permite:

a) Elaborar una regulación unitaria y especifica para cada tipo contractual en particular, y

b) Establecer clasificaciones contractuales de carácter general. Por ejemplo, entre contratos consensuales, contratos rea les; contratos formales, contratos no formales; contratos onerosos, contratos gratuitos (...) etc.".

38 Lo pone de relieve COCA PAYERAS, Op. Cit., Mutuo, p. 4372. 
para, posteriormente, pasar al análisis del contrato de crédito al consumo.

En la mayoría de las legislaciones europeas, el contrato de crédito es de regulación tardía, se tipifica en leyes especiales, aparte de los códigos (civiles y de comercio), precisamente con ocasión de la obligación de incorporar la Directiva $87 / 102 / C E E$. La falta de tipificación, con todo, no implicaba un juicio negativo sobre el contrato sino solo la ausencia de una regulación específica del mismo (atipicidad). El contrato de crédito, era un contrato atípico, creado al amparo de la autonomía de la voluntad (libertad o poder de reglamentación, artículo 1255 del Código Civil ${ }^{39}$ español), que se incluía, generalmente, entre los contratos/operaciones bancarias más practicadas, ya como contrato autónomo ya vinculado a alguna de estas actividades económicas. La falta de tipificación no suponía carencia de regulación, aparte de la derivada de la voluntad privada (autonomía) se le aplicaba toda la normativa sobre las entidades crediticias y en general las que ordenaban las operaciones de crédito y financiación.

A partir de la incorporación de la Directiva, no solo se tipifica el contrato específico de crédito al consumo, sino que al menos en lo que se refiere a los mínimos, se aproximan (armonizan) los ordenamientos de los diferentes Estados miembros. Aunque las discrepancias entre unos y otros, las prácticas y el desarrollo del mercado son las que han dado impulso a la Directiva 2008/48/CEE, en la que sí se ha tomado como modelo la legislación de algún concreto Estado. ${ }^{40}$
No existe una descripción legal, en el ordenamiento español, del contrato de crédito. Pero la más general, que acostumbra a seguir la doctrina, es la que ofreciera GARRIGUES ${ }^{41}$ acerca de la apertura de crédito. Indicaba el profesor que era el contrato mediante el que "(...) el banco se obliga, dentro del límite pactado y mediante una comisión que percibe del cliente, a poner a disposición de éste, y a medida de sus requerimientos, sumas de dinero o realizar otras prestaciones que le permitan obtenerlo al cliente". Completan esta descripción otros datos que indica el mismo autor que sirven para acabar de matizar el concepto jurídico del contrato. De una parte el factor tiempo: el acreditante realiza la prestación y pasa a ser acreedor mientras el acreditado adquiere la propiedad de la cosa que se obliga a devolver (deuda) en el término o términos pactados. De otra, la valoración económica del tiempo (mediante una comisión que percibe del cliente), junto al posible pacto de intereses (onierosidad del contrato) que; al menos en el ordenamiento español cuando se trata de un crédito mercantil, siempre existen (no así en el civil que generalmente es gratuito).

De lo explicado se siguen los caracteres que se predican de este contrato, atributos que lo diferencian del contrato de préstamo mutuo, en cuyo seno se entronca. En síntesis, ya que son suficientemente conocidos ${ }^{42}$, el de crédito es un contrato:

- Consensual: frente al préstamo mutuo codificado, se admite no solo la vinculación contractual sino también. la producción

39 En este precepto se dice:"Los contratantes pueden establecer los pactos, cláusulas y condiciones que tengan por conveniente, siempre que no sean contrarios a las leyes, a la moral, ni al orden público".

40 La influencia más notable que se aprecia en esta Directiva es la de la ley alemana de crédito al consumo (Verbraucherkredigesetz de 17 de diciembre de 1990), tanto en sí misma como en la doctrina que se desarrolló en torno a ella.

41 GARRIGUES, Joaquín, Contratos bancarios, Segunda Edición (revisada y puesta al día por MOLL, S.), Edición del autor, Madrid, 1975, pp. 181.

42 Un buen resumen en URIA, Rodrigo, Derecho Mercantil, igésimo primera edición, Editorial Marcial Pons, Madrid, 1994, pp 798 y ss; Vid, también, PUYALTO FRANCO, María José, Generalidades sobre el préstamo bancario de consumo, 2006, id.vLex:VLEX-366055. En: http://www.vlex.com/vid/36605. 
de efectos (el nacimiento de la obligación) desde que concurre el consentimiento: el acuerdo entre acreditante y acreditado en la materia (objeto) del contrato. El prestamista (acreditante) está obligado a poner a disposición del prestatario las sumas pactadas o las demás prestaciones acordadas, desde el pacto, obligación que puede exigir el acreditado.

El consentimiento puede manifestarse oralmente o por escrito, en la práctica la formulación escrita acostumbra a ser habitual (las pólizas bancarias). Estricto sensu, es un contrato consensual y, además no formal. En este contrato rige el principio de libertad de forma ${ }^{43}$, sin perjuicio de las reglas especiales para algunas modalidades del crédito. Este carácter consensual concurre en el contrato de crédito al consumo.

- Bilateral: una parte se obliga a la puesta a disposición del importe del crédito o de las prestaciones y la otra a la devolución, al pago de la comisión y de los intereses. Pese a que el prestamista solo esté obligado a reintegrar las sumas de las que efectivamente haya dispuesto con sus intereses, el contrato es bilateral, y además genera obligaciones recíprocas entre ambas partes. ${ }^{44}$

- Oneroso: el crédito es remunerado. La prestación de intereses, donde se engloban el precio de la utilización del capital ajeno (concepto económico de interés) y el valor de la dilación temporal (dato de la función del crédito) y en su caso, además, el pago de las comisiones correspondientes.
- Intuito personae: es decir que se funda en la confianza que guardan las partes entre sí, de donde su personalismo y los pactos de reserva frente a la insolvencia del deudor, o los pactos de establecimiento de garantías o cláusulas penales, o la cláusula más habitual, de vencimiento anticipado.

Los indices de tipo del contrato de crédito (que determinan su identificación jurídica), en parte se siguen de los caracteres que se han enunciado. No es un índice propio la consensualidad, pues en este contrato no se añade ningún dato adicional al consentimiento. Sí lo es la causa que, como se ha comentado, es onerosa porque los intereses existen, sea cual fuere el concepto que se remunera a través de ellos, además, en su caso, de las comisiones.

Un dato, índice general de tipo, del contrato de crédito es la cualidad del objeto en lo que, también, difiere del préstamo mutuo y hace de este contrato un tipo autónomo de aquel. De una parte, el objeto se ciñe a una suma de dinero, en lo que coincide con el préstamo mutuo, pero las demás cosas fungibles se excluyen, lo que no es de extrañar, dado que es un contrato que se incluye entre los bancarios. De otra, también son objeto de este contrato "otras prestaciones que permitan la obtención del dinero". En esta expresión, que no puede ser más que genérica para dar cabida a todos los supuestos, se encierran los pactos entre las partes que, valorados económicamente, permiten al acreditado (a favor de quien se concede el crédito) tanto efectivamente conseguir una suma de dinero, como un ahorro (el valor económico de la dilación) ${ }^{45}$ del que debiera emplear para la adquisición de un bien o servicio.

43 Que, en el Código Civil español se enuncia en el artículo 1278: "Los contratos serán obligatorios, cualquiera que sea la forma en que se hayan celebrado, siempre que en ellos concurran las condiciones esenciales para su validez".

44 Incluso algún autor, con referencia al préstamo mutuo con interés, entiende que este contrato es sinalagmático. Así, expresamente, LACRUZ BERDEJO, José Luis (SANCHO REBULLIDA, Francisco de Asís; LUNA SERRANO, Agustín; DELGADO ECHEVERRIA, Jesús; RIVERO HERÁNDEZ, Francisco; RAMS ALBESA, Joaquin), Elementos de Derecho Civil, II, 2, Contratos y cuasicontratos. Delito y cuasidelito, Ed. Dykinson, Madrid, 1999 (nueva edición a cargo de RIVERO HERNÁNDEZ, F.), pp. 178.

$45 \mathrm{Vid}$, en general sobre las nociones de crédito, FERNÁNDEZ-ARIAS SHELLY, Carlos; FERNÁNDEZ-ARIAS ALMAGRO, Carlos, Contrato de apertura de crédito. Id.vLex:VLEX-44159217. En: http://www.vlex.com/vid/44159217. 
Adicionalmente se plantea la duda, en el ordenamiento español, acerca de la posible calificación como contrato mercantil dado que se trata de una operación económica que, en la generalidad de los casos, se lleva a cabo por profesionales. No obstante, se ha de recordar que, en este ordenamiento, solo es mercantil el contrato cuando el préstamo se haga a una persona que tenga la calidad de empresario y además sea un préstamo para dicha actividad. El que una de las partes deba ser prestamista, "empresario" según el nomen de las Directivas, no convierte al contrato en el que una de las partes necesariamente es un consumidor en mercantil. La ventaja, en esto, de la normativa comunitaria reside en que la previa calificación de la relación de consumo (que es un presupuesto) obvia la polémica acerca del carácter civil o mercantil del crédito.

La delimitación amplia del tipo contractual de contrato de crédito, que sobre todo se debe a la configuración del objeto (materia contractual) permite un tipo flexible ${ }^{46}$ en el que encuentran cabida, prácticamente todas las operaciones económicas mediante las que se facilita la adquisición de bienes y servicios, bien porque se procuran medios (sumas de dinero); bien porque se arbitran fórmulas técnicas (aplazamiento, facilidades de pago (...)) que permiten la transmisión/adquisición y, en definitiva, el intercambio (que se produce en el mercado). ${ }^{47} \mathrm{La}$ amplitud en la calificación de lo que sea crédito al consumo ha propiciado una cierta confusión a la hora de establecer un régimen jurídico propio para esta operación. Problema con el que se ha encontrado la Unión Europea a la hora de apreciar cómo se ha llevado a efecto la incorporación de la Directiva 87/102/CEE y valorar las distintas prácticas crediticias que se han desarrollado en el mercado, que han obligado a replantearse la configuración inicial del contrato.
Se ha de distinguir, claramente, para evitar la confusión posible, entre la actividad económica crediticia y el contrato de crédito. Aquella puede tener, $y$ de hecho tiene reflejo jurídico y normativo, a parte del contrato de crédito en otros contratos tipificados. En realidad, los diversos tipos contractuales codificados (tipificados) y los que se contienen en leyes privadas, mediante los que se transmiten derechos o se comprometen actividades (obras, servicios) permiten pactos entre las partes (contenido dispositivo y voluntario del contrato) que en sentido amplio comportan una suerte de concesión de crédito. A título de ejemplo baste mencionar las primeras leyes sobre las ventas a plazos de bienes muebles, y sin alejarnos de los textos codificados, los pactos en los contratos de compraventa sobre aplazamiento del precio y otros similares. En toda adquisición puesto que son las partes quienes, voluntariamente, fijan la ley del contrato (artículo 1091 del Código Civil Españo ${ }^{48}$ ) siempre existe o puede existir un crédito en sentido amplio: la facilidad de pago. Lo que es distinto, y debe deslindarse, del contrato de crédito en sentido estricto cuyo objeto (materia) es, precisamente, la disponibilidad (puesta a disposición) de numerario o la facilitación de la adquisición mediante el juego del transcurso del tiempo (dilación). Con esto quiero decir que el contrato de crédito debe reservarse para aquellos acuerdos que no tienen cabida en otro tipo contractual. Contrato de crédito en el que, frente a los demás tipos contractuales, se ha de destacar la función crediticia de disponibilidad (activa o por ahorro).

Esta constatación no empece que sea necesario armonizar las normas que rigen los contratos en los que se realizan funciones crediticias con el contrato de crédito en general. No sólo la coordinación es necesaria sino obligada para

46 En verdad, en la teoría del tipo contractual, la utilización del tipo para tipificar ya comporta, per se, la flexibilidad, frente a la noción más cerrada o rígida de concepto. Sobre estás cuestiones me remito a GETE-ALONSO Y CALERA, María del Carmen, Op. Cit., Estudios sobre el contrato, en especial los capitulos I y II.

47 De ahí que la quiebra de la confianza en el crédito sea la que origine crisis económicas, como la actual (2008, 2009).

48 Se dice en este precepto (artículo 1091 del Código Civil español), de manera muy gráfica: "Las obligaciones que nacen de los contratos tienen fuerza de ley entre las partes contratantes, y deben cumplirse al tenor de los mismos". 
evitar contradicciones y para impedir posibles fraudes.

A título de ejemplo, se acostumbran a incluir en el crédito ${ }^{49}$, el contrato de mutuo, la renta vitalicia, el depósito irregular, los contratos bancarios de crédito en cuenta corriente, el descuento, el anticipo o descubierto, el factoring, el arrendamiento financiero (leasing), compraventa con pagos a plazos, compraventa con pacto de recompra, las compras mediante tarjeta de crédito, créditos simples y en cuenta corriente, anticipos, operaciones de descubierto, excedidos de cuentas, descuentos (...) etc.

Algunas de estas operaciones son contratos con tipo propio, otras, mientras no exista una regulación separada, se han de reconducir al contrato de crédito que se erige como el tipo contractual base.

\section{EL CONTRATO DE CRÉdITO AL CONSUMO}

Hay quien dice ${ }^{50}$ que el contrato de crédito al consumo no tiene caracterización propia y que, por lo general se reduce a dos contratos básicos, el de compraventa y el de crédito personal. Dada la normativa con la que se cuenta, a día de hoy, sobre este contrato, y la constatación de la práctica del mercado ${ }^{51}$ está claro que no se reduce a dos modalidades sino que, como se acaba de comentar supra, la materia (objeto) que comprende, es más amplio. Se engloban en este contrato todas aquellas modalidades crediticias que no tienen cabida en un contrato particular tipificado.

Son esclarecedoras las palabras de explicación del porqué de la nueva Directiva 2008/48/ CEE ${ }^{52}$ : "En los últimos años han cambiado con- siderablemente los tipos de crédito ofrecidos a los consumidores y utilizados por ellos. Han aparecido nuevos instrumentos de crédito y su uso sigue desarrollándose. Conviene, pues, modificar las disposiciones vigentes y, en caso necesario, ampliar su ámbito de aplicación".

La extensión del ámbito comporta variaciones en la tipificación del contrato. Veamos cuales son.

\section{Datos legales de configuración}

Los datos legales de configuración del contrato del crédito al consumo se contienen en la descripción del mismo del artículo 3 c de la Directiva 2008/48/CEE. Estos determinan el tipo contractual pero no el régimen particular del contrato de crédito al consumo al que se le ha de aplicar las reglas previstas en la Directiva.

Recordemos que bajo el contrato de crédito al consumo se comprenden diferentes supuestos:

- El tipo contractual autónomo de crédito al consumo.

- El tipo contractual contrato de crédito al consumo vinculado.

- Los contratos de crédito al consumo con limitaciones del régimen.

- Tipos contractuales de crédito al consumo excluidos.

Dicho de otra forma, la manera en que se ha regulado el contrato de crédito al consumo, que a fin de cuentas es una opción que ha elegido el legislador por la razón que sea, obliga a discriminar entre tipificación del contrato y régimen jurídico de este. Mientras en la tipificación se sigue el criterio amplio del contrato de crédito que

49 RIVERO ALEMAN, Op. Cit., Crédito, Consumo, pp. 195 y 329 y ss.

50 RIVERO ALEMAN, Op. Cit., Crédito, Consumo, pp. 197 y ss.

51 Pese a que las circunstancias económicas durante el año 2008 , el presente 2009 y, según se comenta, también el 2010 , hayan supuesto un freno importante a determinados contratos de crédito al consumo, en especial a los créditos personales.

52 Considerando 5 
se ha comentado, se adopta la fragmentación por lo que hace al régimen. Una fragmentación que si bien, en un primer momento es útil, en la medida en que facilita la adecuación al supuesto concreto, se torna en peligrosa en cuanto las circunstancias, sobre todo económicas varían y, entonces, comprometen al legislador a reformar una vez más, lo no siempre es aconsejable pues el principio de seguridad jurídica (y el de seriedad) reclama estabilidad en las normas, o sea que se mantengan inalteradas un tiempo más o menos largo para comprobar su efectividad. Esto solo se consigue si la formulación de la regla jurídica y del supuesto de hecho es general, abstracta si se quiere, no en el excesivo apego al casuismo en que caen, desafortunadamente, la mayor parte de las Directivas.

Conforme a la Directiva 2008/48/CEE (artículo 3 c) se entiende como contrato de crédito aquel “(...) mediante el cual un prestamista concede o se compromete a conceder a un consumidor un crédito en forma de pago aplazado, préstamo u otra facilidad de pago similar, exceptuados los contratos para la prestación continuada de servicios o para el suministro de bienes de un mismo tipo en el marco de los cuales el consumidor paga por tales bienes o servicios de manera escalonada mientras dure la prestación".

La definición del contrato de crédito al consumo coincide con la general del contrato de crédito, de donde se predican de aquel los caracteres que se han comentado.

Obsérvese que la calificación de "contrato de consumo" se hace depender de la cualidad en la que intervienen las partes en el contrato (prestamistaconsumidor), lo que no es un índice del tipo contractual sino, como se apuntó, un presupuesto para que se apliquen las reglas de consumo. Por demás, la fórmula empleada manifiesta un ámbito de aplicación que se delimita de manera amplia pero que, a la vez, se delimita.

a) El contrato de crédito al consumo abarca los dos tipos contractuales, al menos en lo que afecta al régimen de protección, el crédito consensual (se compromete a conceder) y el préstamo mutuo codificado (concede).

b) Por lo que se refiere a la materia (objeto) del contrato de crédito, la definición es amplia. En la descripción se comprenden las principales operaciones económicas (formas de crédito) que comportan la calificación jurídica:

El aplazamiento de pago, que quizá es el medio más tradicional de facilitar/permitir la adquisición: alargamiento del tiempo de cumplimiento de la obligación de pago del precio. Se tiene en cuenta, aquí, el valor económico de la dilación y no importa cual sea y cómo, bien mediante el fraccionamiento en parte (plazos) de la deuda, bien mediante la suspensión de la exigencia del pago, ya por el otorgamiento de un derecho (...), etc.

- El préstamo: donde la llamada es al contrato de mutuo en su doble consideración consensual (concede) y real (promete). La remisión es al préstamo de dinero, entrega de una suma, puesta a disposición (disponibilidad).

- En último lugar, la clave de cierre del sistema, otra facilidad de pago diferente del aplazamiento. ${ }^{53} \mathrm{~A}$ esta descripción, que era la de la Directiva $87 / 102 /$ CEE, se ha añadido una precisión respecto de un objeto que ya se mencionaba en esta pero que se concreta y determina el objeto (materia). Se excluyen, porque no son contratos de crédito sino que pertenecen a otra tipificación contractual:

- Los contratos de obra y servicios en los que se haya pactado el pago a medida que se realiza la prestación y mientras no termine la prestación (actividad) comprometida. La razón es obvia y no requiere demasiada explicación pues si la actividad comprometida se cumple continuadamente (tracto continuo) a lo largo del tiempo, la distribución en tiempo sucesivo del pago no comporta crédito ni facilidad de pago alguna sino prestación periódica.

53 Respecto de la Directiva 87/102/CEE y la Ley 7/1995 LCC española, vid, DIEZ-PICAZO y PONCE DE LEÓN, Luis, Contratos de crédito y protección de consumidores. En Anuario de Derecho Civil, LII, Fascículo IV, 1999, pp.1357 a 1394. 
- También, quedan al margen los contratos de suministro de bienes aunque se pague, como dice la norma "de manera escalonada mientras dure la prestación". La misma razón que se ha explicado para el caso anterior justifica que estos contratos no se consideren, jurídicamente, de crédito.

Se indica ${ }^{54}$ que estos contratos "(...) pueden presentar grandes diferencias, tanto en lo que se refiere a los intereses de las partes contratantes como a las modalidades y la ejecución de las operaciones, en comparación con los contratos de crédito cubiertos por la presente Directiva. Conviene, por tanto, precisar que tales contratos no son considerados contratos de crédito a los efectos de la presente Directiva". Y a continuación pone un ejemplo que no se aviene, realmente, con los contratos que se excluyen, efectivamente, en el texto normativo de la Directiva. Se dice que "(A) esta categoría de contratos pertenecen los contratos de seguros en los que el seguro se paga mediante cuotas mensuales". Como es sabido, el contrato de seguro ni compromete una prestación continuada de servicios, ni suministro de bienes alguno, y se excluye, en verdad, valga la perogrullada, porque es un tipo contractual de seguro que no contiene crédito (aunque sea del tipo de crédito o caución $)^{55}$ y ni siquiera es posible considerar que comporta una forma de crédito.

Podría argumentarse que el fraccionamiento en el pago de la prima (que es única) (obligación del tomador del seguro) es una facilidad de pago $y$, por lo tanto, un crédito tal y como se define por la Directiva 200/48, y que es a esta obligación (deuda) a la que se refiere la frase del ejemplo. Con todo, quizá esa fuera la intención, es decir que el contrato de seguro quedara excluido cuando el pago de la prima se pactara en plazos continuos; pero esta intención no encuentra acomodo en la descripción del contrato de crédito del articulado. El pago escalonado de la prima (facilidad = crédito) es el precio que no es a cambio de un bien o servicio que se presta escalonadamente sino contrapartida de la asunción del riesgo de la compañía (sociedad) aseguradora. La parte aseguradora se obliga a pagar una suma dineraria (indemnización) cuando se produzca el riesgo contratado, hasta ese momento no realiza ninguna prestación, entre otras razones porque si bien está vinculada contractualmente, la prestación no existe jurídicamente (aleas). ${ }^{56}$

La larga lista de créditos que se excluyen por completo, o parcialmente por el artículo 2.2 no afecta a la configuración (tipificación) del contrato de crédito al consumo sino al régimen del contrato/crédito exceptuado, que no se altera (es el ordinario) porque una de las partes sea consumidor. Respecto de los contratos para los que se limita la aplicación del régimen de protección al consumidor, tampoco comporta variación de la calificación. Es decir, teóricamente en el contrato de crédito al consumo se han de incorporar aquellos a los que no se aplica, total o parcialmente, la Directiva, precisamente porque la llamada a la exclusión denota que sí son créditos al consumo. En definitiva, la diversificación entre el tipo/tipos contractuales y el régimen.

En un orden sistemático, de los enumerados en el artículo 2.2 según la Directiva 2008/48/CEE son contratos de crédito y, añado, contratos de crédito al consumo que, en algún momento, o por alguna legislación pueden estar sometidos a la normativa de consumo, además de los de importe total inferior a $200 €$ o superior a $75.000 €$, y aquellos en que el reembolso se efectúa en un plazo breve:

Los destinados a la adquisición, conservación (créditos refaccionarios) de bienes inmuebles

54 Considerando 12

55 Ley 50/1980, de 8 de octubre, del Contrato de Seguros (LCS), artículo 68 (seguro de caución) y artículo 69 (seguro de crédito).

56 Sobre el concepto de aleas, el funcionamiento y el medio técnico me remito a lo que expliqué en: Op. Cit., Estructura y Función, pp. 550 y ss. 
(fincas y edificios) y los garantizados con hipoteca u otro derecho de garantía real inmobiliaria. También, los contratos garantizados con prenda u otro tipo de garantía que comporte entrega del bien al prestamista y en los que se limite la responsabilidad al bien entregado. En definitiva, los préstamos garantizados con derechos reales (mobiliarios e inmobiliarios).

- Los contratos de arrendamiento o de arrendamiento financiero tanto en los que exista obligación de compra del objeto del contrato, como en los que no se haya previsto.

- Las facilidades de descubiertos y los descubiertos en cuenta.

- Los créditos gratuitos concedidos libres de intereses y sin ningún otro tipo de gastos o con gastos mínimos y los contratos para facilitar el pago aplazado de una deuda previa, sin gastos. Por razón de la cualidad del prestamista (que no es un profesional del crédito) o de la intervención de determinados poderes, pese a la especificidad, también se engloban entre los créditos al consumo:

- Los que concede un empresario a los trabajadores, en el ámbito de la relación laboral;

- Los celebrados con empresas de inversión los que son el resultado de un acuerdo alcanzado en los tribunales o ante cualquier otra autoridad pública y

- Los concedidos en virtud de una disposición legal a un público restringido, con un objetivo de interés general, y a un tipo de interés inferior al habitual.

Una mera comparación entre los contratos excluidos en la Directiva 87/102/CEE y los de la Directiva 2008/48/CEE pone de relieve la ampliación del concepto de crédito al consumo que se ha operado en esta. Un concepto que se resume, de manera bastante clara, en los tres datos de la descripción general: préstamo-aplazamientofacilidad de pago.

De la lista, además, se sigue que los criterios subjetivos y los cuantitativos a los que se alude por alguna doctrina ${ }^{57}$ son indiferentes de cara a la tipificación del contrato cómo de crédito al consumo.

Los subjetivos, se ha dicho ya, porque son presupuesto previo de incardinación de las relaciones contractuales en el ámbito de la normativa de consumo, y los cuantitativos porque matizan el alcance del régimen, pero no de manera absoluta.

En cuanto a la onerosidad/gratuidad del contrato de crédito, en sí tampoco es un dato especíicico de tipificación, en el tipo amplio tienen cabida ambas funciones económicas. No obstante, es cierto que por lo que atañe al régimen sí afecta; la ausencia de onerosidad determina, al menos momentáneamente, la exclusión del régimen o la matización.

Parecidamente sucede en lo que afecta a la dilación temporal, el período que transcurre entre la perfección del contrato, la producción de efectos y el cumplimiento total de la obligación de devolución o del pago del precio, que tiene un valor económico diferente del que corresponde a los intereses (valor de la utilización del capital ajeno). Es un dato que determina la exclusión o matización del régimen (los reembolsos rápidos y plazos cortos se excluyen).

\section{El régimen jurídico mínimo}

El régimen jurídico mínimo del contrato de crédito al consumo que prevé la Directiva 200/48 aborda, en esencia, las mismas cuestiones que la Directiva $87 / 102 / C E E$, pero, además de reforzar la obligatoriedad de incorporación por los Estados miembros, extiende la protección de manera considerable. Este régimen constituye un contenido imperativo básico de la relación contractual de consumo a la que alcanza la norma comunitaria. Conviene recordar, a fuer de ser reiterativa, que aunque el tipo jurídico de este contrato sea flexible, tal y como resulta de la propia normativa, solo los que específicamente esta considera, están sometidos a la misma. Para algunos contratos de crédito, se ha comentado ya, se disponen restricciones $y$, a la vez, reglas

57 En particular RIVERO ALEMAN, Op. Cit., Crédito, Consumo, pp. 197 y ss. 
particulares, y otros solo están sometidos a algunas normas. De ahí que, al objeto de lo que se estudia en este trabajo (la caracterización del contrato de crédito al consumo) aquí solo se haga mención del régimen común..$^{58}$

La ampliación del régimen se manifiesta particularmente en la formación del contrato, aunque alcanza hasta la ejecución. Distingamos la fase precontractual, la perfección del contrato y a partir de la perfección.

1.- En la fase precontractual se refuerza, particularmente, el deber de información que se ha de proporcionar obligatoriamente, que es básico y fundamental. ${ }^{59}$ Deber de información que junto a la transmisión de los datos (información estricto sensu) comprende los de advertencia y consejo (asesoramiento) y las prácticas previas a la celebración del contrato (Capítulo Il de la Directiva 2008/48/CEE). Dos cuestiones se regulan de manera particular:

a) El contenido de la publicidad que se haga de los contratos de crédito. Esta, a la que se aplica la Directiva 2005/29/CEE (prácticas desleales), debe incluir la información básica que se enuncia en el artículo 4 "de forma clara, concisa y destacada mediante un ejemplo representativo", lo que se extiende a la información relativa "a un contrato accesorio vinculado al contrato de crédito" que se obligue a contratar junto al crédito (artículo 4.2., en el que pone el ejemplo de la obligación de suscribir un contrato de seguro).

b) La información precontractual obligada se refuerza y se concreta su contenido. Antes de que el consumidor asuma cualquier obligación en virtud de un contrato $u$ oferta de crédito, con la debida antelación, el prestamista y el intermediario de crédito deberán facilitar al consumidor, sobre la base de las condiciones del crédito ofrecidas, de las preferencias manifestadas y de la información facilitada por el consumidor, la información precisa para comparar las diversas ofertas y adoptar una decisión informada sobre la suscripción de un contrato de crédito. Esta información, que se denomina "Información normalizada europea sobre el crédito al consumo" ha de ser la que se indica en el anexo II, se ha de facilitar en papel o en cualquier otro soporte duradero (artículo 5.1.) y es gratuita. En todo caso, el consumidor tiene derecho a solicitar una copia del proyecto de contrato de crédito (artículo 5.4).

En esta etapa precontractual, además, se imponen al prestamista "para promover unas prácticas responsables en todas las fases de la relación crediticia, teniendo en cuenta las peculiaridades del su mercado crediticio" ${ }^{\prime \prime 0}$ :

- El deber de asesoramiento. Los Estados miembros están obligados a velar (artículo 5.6.) para que prestamistas e intermediarios de crédito faciliten al consumidor las explicaciones adecuadas para que pueda evaluar si el contrato de crédito propuesto se ajusta a sus necesidades y a su situación financiera, si fuera preciso explicando la información precontractual, las características esenciales de los productos propuestos y los efectos especificos, incluidas las consecuencias en caso de impago por parte del consumidor.

- La obligación, en verdad la carga del prestamista de evaluar la solvencia del consumidor (artículo 8). "Los Estados miembros velarán por que, antes de que se celebre el contrato de crédito, el prestamista evalúe la solvencia del consumidor, sobre la base de una información suficiente, facilitada en su caso por el consumidor $y$, cuando proceda, basándose en la consulta de la base de datos pertinente (artículo 8.1)".

58 Un régimen al que quedarán sometidos los contratos de crédito al consumo que ahora se excluyen en el momento en que se decida, lo que puede ocurrir si en la incorporación que se haga por los Estados miembros así lo decidan.

59 Quien tiene la información tiene el poder, porque el conocimiento pone a la persona en situación de decidir consciente y libremente.

60 Considerando 26 de la Directiva 200/48. 
2.- En la fase de perfección se enumera, pormenorizadamente, el contenido que se ha de mencionar en los contratos, que debe expresarse de forma clara y concisa. Se mantiene la necesidad de la forma escrita (papel) a lo que se añade o "en otro soporte duradero" (artículo 10).

La innovación más significativa que aporta la Directiva 2008/48/CEE es la atribución al consumidor del derecho de desistimiento del contrato. Como en otras relaciones contractuales de consumo para las que se reconoce, el desistimiento no exige la alegación de motivo o justificación y puede ejercitarse en un plazo de 14 días cuyo cómputo se inicia en la fecha de celebración del contrato, o en la fecha en que el consumidor reciba las condiciones contractuales y la información (artículo14).

3.- Perfeccionado el contrato, la nueva Directiva regula en particular algunas cuestiones:

- Se obliga al prestamista a informar de toda modificación del tipo deudor mediante documento en papel u otro soporte duradero (artículo 11).

- En los contratos de crédito de duración indefinida se otorga al consumidor el derecho a poner fin al contrato, gratuitamente y en cualquier momento (artículo 13).

- Asimismo, el consumidor tiene derecho al reembolso anticipado (artículo 16): "derecho a liquidar en todo momento, total o parcialmente, las obligaciones derivadas del contrato de crédito. En tales casos, tendrá derecho a una reducción del coste total del crédito, que comprende los intereses y costes correspondientes a la duración del contrato que quede por transcurrir" (apartado 1).

- En cuanto al supuesto de cesión de créditos, que ya se regulaba en la anterior Directiva, expresamente se prevé que el consumidor pueda hacer valer ante el nuevo titular las mismas excepciones y defensas que ante el prestamista originario (artículo 17). Un contenido mínimo del régimen que tiene un fuerte componente imperativo que contribuye a identificar al tipo contractual.

Este elenco de derechos se completa con el carácter obligatorio que tienen las determinaciones de la Directiva 200/48/CEE y con dos imposiciones de índole general, ambas referidas en el artículo 22.

- El carácter de derechos irrenunciables de aquellos que se atribuyan al consumidor "en virtud de las disposiciones nacionales que den cumplimiento o correspondan a la presente Directiva" (apartado 2).

- La prevención del fraude, que, aunque se recogía en la Directiva $87 / 102 / \mathrm{CEE}^{61}$, ahora se expresa más directamente. Indica el apartado 3 del artículo 22: "Los Estados miembros garantizarán además que las disposiciones que adopten para dar cumplimiento a la presente Directiva no puedan eludirse de resultas del modo en que se formulen los contratos, especialmente como consecuencia de la integración de operaciones de disposición de fondos o contratos de crédito sujetos a la presente Directiva en contratos de crédito cuyo carácter u objetivo permita sustraerlos a su ámbito de aplicación".

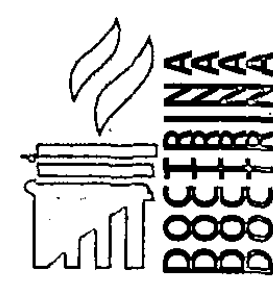

61 Artículo 14:

"1. Los Estados miembros garantizarán que los contratos de crédito no se sustraigan, en perjuicio del consumidor, a las disposiciones de la legislación nacional que apliquen o que correspondan a la presente Directiva.

2. Los Estados miembros garantizarán además que las disposiciones que adopten para la aplicación de la presente Directiva no sean eludidas como consecuencia de la forma en que se otorguen los contratos, y en particular mediante el procedimiento de distribución de la cuantía del crédito entre varios contratos". 